\title{
DUAS FORMAS DE INTERTEXTUALIDADE EM CARTAS AO EDITOR EM NEWSWEEK
}

\author{
Maurício Moreira CARDOSO \\ lmmcardoso@yahoo.com.br
}

\begin{abstract}
Resumo: Este artigo é uma análise de duas formas de intertextualidade, a pressuposição e a ironia, no corpus de 122 cartas ao editor extraídas da revista Newsweek. A fim de levar a termo a análise, buscamos suporte nas teorias de Bakhtin (1986, 2000), Orlandi (2001), Bronckart (2003) e Maingueneau (1997, 2001). Analisamos quantitativamente e qualitativamente 122 cartas endereçadas à revista no período entre julho e dezembro de 2002. Em relação a esse aspecto, observamos que as formas de intertextualidade referentes ao artigo ou reportagem têm uma conexão direta com o desenvolvimento da argumentação. As formas de intertextualidade são ligadas à linha argumentativa do texto, embora, algumas vezes, não estejam claramente presentes no corpo da carta.
\end{abstract}

Palavras-chave: discurso, cartas ao editor, intertextualidade, pressuposição, ironia

Abstract: This article is an analysis of two forms of intertextuality, presupposition and irony, in the corpus of 122 letters to the editor taken from the Newsweek magazine. In order to accomplish the analysis, we got support of the theories of Bakthin (1986, 2000), Orlandi (2001), Bronckart (2003) and Maingueneau (1997, 2001). We analyzed, quantitatively and qualitatively, 122 letters to the magazine in the period between July and December of 2002. With regards to this aspect, we observed that the forms of intertextuality referring to the article or report have a direct connection with the development of the argumentation. The forms of intertextuality are connected to the argumentative line of the text, although sometimes they are not clearly presented in the body of the letter.

Key-words: Discourse, letters to the editor, intertextuality, presupposition, irony 


\section{Introdução}

Este artigo é parte da Dissertação de Mestrado ${ }^{1}$ que teve por objetivo analisar as cartas ao editor coletadas da revista Newsweek no período compreendido entre julho a dezembro de $2002,{ }^{2}$ com o fim de verificar como o jogo sócio-interacional entre leitor e editor se acha refletido nas estratégias discursivas comuns a esse gênero discursivo. Para este fim, baseando-nos principalmente em Bakhtin (1986, 2000), Orlandi (2001), Bronckart (2003) e Maingueneau (1997, 2001) buscamos suporte teórico na área do conhecimento da Análise do Discurso, que considera um texto necessariamente ligado aos propósitos determinados pelos eventos humanos e destinado a produzir significações, não alheias à prática social. Analisamos, qualitativa e quantitativamente, 122 cartas da referida revista no período compreendido entre julho e dezembro de 2002, detendo-nos em basicamente três aspectos: (a) características contextuais do gênero carta ao editor; (b) formas de heterogeneidade mostrada usadas como forma de remissão ao texto-base; e (c) relevância discursiva da identificação do leitor.

As cartas ao leitor constituem, como sabemos, um espaço que em jornais e revistas é destinado à manifestação dos leitores. São, assim, um importante instrumento da afirmação do princípio da democracia burguesa e da cidadania. E é notadamente a existência desse espaço criado para a manifestação do leitor, o ponto irradiador e, ao mesmo tempo, convergente de inúmeros fenômenos estudados através da Análise do Discurso e da Lingüística Textual. Dessa forma, a superestrutura da forma de poder (o poder da comunicação escrita), que é a imprensa, é compartilhada por todos os indivíduos capazes de se expressarem por meio do idioma utilizado pela referida superestrutura inscrita em determinado espaço e tempo. Por esse motivo, as cartas endereçadas aos editores de jornais e revistas constituem, a nosso ver, uma importante fonte de leitura e interpretação de determinado grupo

\footnotetext{
${ }^{1}$ Cardoso, 2005.

${ }^{2}$ Esse período foi marcado pela existência de diversos conflitos como a invasão do Afeganistão pelos Estados Unidos, o conflito entre Rússia e Chechênia, os preparativos para a invasão do Iraque, o conflito entre Índia e Paquistão, entre outros.
} 
social, mesmo que tal grupo não se caracterize por compartilhar o mesmo espaço geográfico, como é o caso de leitores de jornais e revistas cuja circulação é mundial, como, por exemplo, a revista que selecionamos.

\section{A ironia e a pressuposição}

O presente artigo é uma análise de duas formas de intertextualidade remissivas ao texto-base encontradas em nossa pesquisa: a pressuposição e a ironia. A escolha dessas duas formas de remissão ao texto-base se justifica pelos dados estatísticos que levantamos. As referidas formas de remissão se configuram como a mais e a menos utilizada, respectivamente. Estabelecida essa relação, queremos problematizar em torno da escolha feita pelos leitores missivistas da forma de remissão mais adequada aos seus objetivos argumentativos, bem como dos aspectos sócio-culturais que podem estar envolvidos nessas escolhas. No desenvolvimento de nossa pesquisa, detectamos as seguintes formas de remissão ao texto-base, feitas pelos leitores-missivistas do referido corpus: pressuposição, negação, ironia, referência ao título, alusão ao tema, paráfrase e excerto 3 . Para uma vista panorâmica da heterogeneidade no corpus escolhido, vejamos a tabela abaixo que indica a porcentagem das caracterizações da intertextualidade encontrada nas revistas em estudo:

\begin{tabular}{|l|r|r|}
\hline tipo de intertextualidade & \multicolumn{1}{|c|}{$\mathrm{N}^{\circ}$} & \multicolumn{1}{c|}{$\%$} \\
\hline paráfrase & 23 & 18,9 \\
referência ao título & 19 & 15,6 \\
excerto & 20 & 16,4 \\
alusão ao tema & 12 & 9,8 \\
negação & 13 & 10,7 \\
pressuposição & 33 & 27,0 \\
ironia & 2 & 1,6 \\
Total & 122 & 100,0 \\
\hline
\end{tabular}

Tabela: intertextualidade com texto original 
Como podemos observar, a forma mais comum de remissão com o texto-base é a pressuposição (33/122 ou 27,0\%), seguida pela paráfrase $(23 / 122$ ou $18,9 \%)$. A forma de heterogeneidade menos utilizada é a ironia (2/122 ou 1,6\%). Para efeito desta análise, conforme explicamos acima, selecionamos apenas a ironia e a pressuposição.

\section{A heterogeneidade e o dialogismo}

Para a análise das formas de intertextualidade remissivas ao texto que originou a carta ao editor, nas cartas da revista Newsweek, é central entender não só como o leitor-missivista faz remissão ao texto a que sua carta se refere, mas também o porquê da forma de remissão escolhida. Neste sentido, apesar de o caráter intertextual e o dialógico fazerem parte de qualquer enunciado (BAKHTIN, 2000; MAINGUENEAU, 1997), pretendemos estudá-los em suas formas de manifestação mais específicas - a heterogeneidade mostrada e o dialogismo circunscritos à relação direta entre o texto-base (artigo, reportagem da revista) e a carta a ele correspondente.

Nesse sentido, interessa, em particular, investigar a interação leitor/editor, tomando como base a obra de Bakhtin (2000), quanto à sua noção de intertextualidade e dialogismo. Um aspecto não necessariamente intrínseco aos gêneros do discurso, mas aos textos em geral, é a noção de intertextualidade. Os textos mantêm relações com outros textos que lhes são externos, exteriores a ele, todavia, por algum viés, trazidos para dentro dele.

Para começarmos a discorrer sobre a noção de intertextualidade, não podemos deixar de mencionar o pensamento de Bakhtin (2000). Na linha de pensamento deste autor, uma noção fundamental é a de dialogismo. Sobre essa noção, assevera Bakhtin (2000, p. 294):

o diálogo, por sua clareza e simplicidade, é a forma clássica da comunicação verbal. Cada réplica, por mais breve e fragmentária que seja, possui um acabamento especifico que expressa a posição do locutor, sendo possivel responder, sendo possivel tomar, com relação a essa réplica, uma posição responsiva. 
Ora, para o autor não existe enunciado que tenha partido do nada, tendo necessariamente que se configurar como uma resposta a outro enunciado, pois o que caracteriza o diálogo é a alternância de sujeitos falantes. Neste sentido, um dado texto nasce sempre de outro texto, direta ou indiretamente. Em outras palavras, qualquer texto traz sempre elementos de outro, ou de outros textos. Cabe aqui, mais uma vez, citar Bakhtin (2000, p. 317) que acrescenta o seguinte à noção de enunciado:
a expressividade de um enunciado é sempre, em menor ou maior grau, uma resposta, em outras palavras: manifesta não só sua própria relação com relação ao objeto enunciado, mas também a relação do locutor com os enunciados do outro.

Assim, os textos que constantemente se instauram são a materialização das necessidades comunicativas entre sujeitos. O sentido mais usual com que apreendemos este entrelace de textos é concernente às citações, "a presença de elementos reais de outros textos em um dado texto" (FAIRCLOUGH, 2001, p. 39). Todavia as relações intertextuais nem sempre são tão explícitas quanto nas citações. Existem outros modos menos claros e menos diretos de incorporar elementos de outros textos. Fairclough ilustra com o discurso reportado, em que é possível não apenas citar o que fora dito, mas também resumir, fazer paráfrases, de modo que o texto original de algum modo se retextualiza. Assevera o autor:

o discurso relatado, escrito ou pensado, atribui aquilo que é citado on sumarizado às pessoas que o proferiram, escreveram ou o pensaram. Mas elementos de outros textos podem ser incorporados sem atribuição. Assim, a intertextualidade cobre uma ampla gama de possibilidades. (FAIRCLOUGH, 2001, p. 40) ${ }^{4}$

\footnotetext{
${ }^{3} \mathrm{O}$ que aqui se chama de excerto corresponde às "palavras entre aspas" na fundamentação teórica adotada.

${ }^{4}$ Reported speech writing or thought attributes what is quoted or summarized to the person who said or wrote or thought it. But elements of other texts may also be incorporated without attribution. So intertextuality covers a range of possibilities (2001, p. 40).
} 
Em outras palavras, é muito difícil tipificar a intertextualidade. O fenômeno cobre desde citações literais, passando por discursos indiretos até o extremo em que a apropriação discursiva só pode ser reconhecida mediante o conhecimento prévio do leitor. A orientação para a diferença leva-nos às formas dialógicas nos textos. Neste particular, Fairclough segue de perto Bakhtin, para o qual uma palavra, um discurso, uma língua ou uma cultura trazem subjacente o dialogismo. Qualquer enunciado, como dito anteriormente, é um vínculo numa complexa cadeia organizada de outros enunciados.

No entanto, Bakhtin ressalta que:

o estudo fecundo do diálogo pressupõe, entretanto, uma investigação mais profunda das formas usadas na citação do discurso, uma vez. que essas formas refletem tendências básicas e constantes da recepção ativa do discurso de outrem, e é essa recepção, afinal, que é fundamental também para o diálogo. (1986, p. 147)

Mas, como afinal o discurso de outrem é apreendido pelo locutor? $\mathrm{O}$ mencionado lingüista russo sustenta que é exatamente nas formas do discurso citado que podemos encontrar um documento objetivo que esclarece o problema. Esse documento, observa Bakhtin, fornece indicações sobre as tendências sociais estáveis características da apreensão ativa do discurso de outrem que se manifestam nas formas da língua, pois é na sociedade que se situa o mecanismo do processo da intertextualidade. A sociedade

escolhe e gramaticaliza apenas os elementos da apreensão ativa, apreciativa, da enunciação de outrem que são socialmente pertinentes e constantes e que, por conseqüência, têm seu fundamento na existência econômica de uma comunidade lingüistica dada. (BAKHTIN, 1986, p. 146)

A isso devemos acrescentar o fato de que na transmissão sob forma escrita da enunciação de outrem deve ser levada em consideração a pessoa a quem está sendo transmitida tal enunciação, pois a orientação para uma terceira pessoa reforça a influências das forças sociais organizadas sobre o modo de apreensão do discurso. Nesse sentido, é curioso observar como numa situação real de diálogo, ao respondermos a um interlocutor, habitualmente não retomamos 
no nosso enunciado o enunciado, ou parte do enunciado, de nosso interlocutor.

Para Bakhtin, "as condições de transmissão e suas finalidades apenas contribuem para a realização daquilo que já está inscrito nas tendências da apreensão ativa, no quadro do discurso interior" (1986, p. 146). Tais tendências, aprofunda o autor, só podem desenvolver-se obedecendo os limites das formas existentes numa determinada língua para a transmissão do discurso.

O citado autor esclarece que as formas de transmissão do discurso de outrem, uma vez cristalizadas, exercem uma influência reguladora, estimulante ou inibidora no desenvolvimento das tendências de apreensão apreciativa, cujo campo de ação é justamente definido por essas formas. Essa informação é importante no sentido de responder a indagação feita acerca da preferência sobre determinadas formas em dado gênero, enquanto outras tendem para o desuso.

Contudo, Bakhtin observa que "toda a essência da apreensão apreciativa da enunciação de outrem, tudo o que pode ser ideologicamente significativo tem sua expressão no discurso interior" (1986, p. 147), pois o enunciado alheio sofre, no interior do indivíduo que o apreende, uma re-elaboração que acontece em termos do seu background cultural, de sua formação como ser social. Assim, é que o enunciado citado só pode ser corretamente entendido, quando estudado no interior do discurso que o cita. Em outras palavras, o discurso citado não pode ser divorciado do seu contexto narrativo, pois a interação dinâmica das duas dimensões, o discurso a transmitir e aquele que serve para transmiti-lo, é fundamental para quem deseja entender o fenômeno da intertextualidade. Essa interação dinâmica, por sua vez, é reflexo da dinâmica da inter-relação social dos indivíduos na comunidade ideológica verbal (BAKHTIN, 1986). Cabe lembrar, ainda fazendo referência ao eminente lingüista russo, que "a língua elabora meios sutis e mais versáteis para permitir ao autor infiltrar suas réplicas e seus comentários no discurso de outrem" (1986, p. 150).

$\mathrm{O}$ referido autor observa ainda que um discurso a ser transmitido obedece a uma hierarquia social de valores. Dessa forma, "quanto mais forte for o sentimento de eminência hierárquica na enunciação de outrem, mais claramente definidas serão suas fronteiras [...]" (BAKHTIN, 1986, p. 153). 
No que diz respeito a essa discussão, Maingueneau (1997), apoiado em Authier-Revuz (apud CHARAUDEAU; MAINGUENEAU, 2004), mostra uma distinção que na prática se revela bastante útil. Trata-se da distinção entre heterogeneidade mostrada e heterogeneidade constitutiva.

Maingueneau começa por dizer que a noção de heterogeneidade é, antes de tudo, fundamental para o entendimento da relação do interior do discurso com seu exterior. Para o entendimento do que é heterogeneidade, importante se faz entender a noção de polifonia em Ducrot (1987). Este autor estabelece uma associação entre polifonia e o nível do enunciado. Em sua perspectiva, só há polifonia quando é possível distinguir em uma enunciação dois tipos de personagens, os enunciadores e os locutores, o que significa que outros pontos de vista além daqueles do emissor e do receptor podem ser veiculados através do enunciado.

Maingueneau (1997, p. 76) esclarece que locutor é "um ser que no enunciado é apresentado como seu responsável. Trata-se de uma ficção discursiva que não coincide necessariamente com o produtor físico do enunciado". No que se refere ao enunciador, Maingueneau (1997, p. 77) explica:

o enunciador representa, de certa forma, frente ao 'locutor' o que o personagem representa para o autor em uma fição. Os 'enunciadores' são seres cujas vozes estão presentes na enunciação sem que se lhes possa, entretanto, atribuir palavras precisas; efetivamente, eles não falam, mas a enunciação permite expressar seu ponto de vista. Ou seja, o 'locutor' pode pôr em cena, em seu próprio enunciado, posições diferentes da sua.

O fenômeno da heterogeneidade se desdobra em algumas formas de ocorrências, que são as seguintes: pressuposição; negação; discurso relatado; palavras entre aspas; metadiscurso do locutor; parafrasagem; discurso indireto livre, ironia; autoridade, provérbio e slogan; pastiche.

Algumas envolvem considerável complexidade, como é o caso da noção de pressuposição, que tem importância considerável para a análise do discurso. Segundo Ducrot (1987), a pressuposição se constitui através de um processo que apresenta dois 'enunciadores', 
E1 e E2; o primeiro é responsável pelo pressuposto, e o segundo, pelo posto.

Exercendo um contraste com o discurso indireto livre, que institui um jogo fronteiriço entre o discurso citado e o discurso que cita, a ironia, de acordo com Maingueneau (1997), configura-se como uma subversão entre o que é assumido e o que não o é pelo locutor. $\mathrm{O}$ "locutor" coloca em cena um "enunciador" que adota uma posição absurda e cuja alocução não pode assumir, marcando esse distanciamento com diferentes índices: lingüísticos, gestuais, situacionais. É da essência da ironia suscitar a ambigüidade, fazendo que, com freqüência, a interpretação não consiga resolvê-la. Sendo sempre dirigida a um destinatário, não pode ser considerada uma atividade lúdica desinteressada.

\subsection{O caráter intertextual do gênero carta ao editor}

A concepção tripartida do discurso, texto, prática discursiva e prática social, Fairclough (2001), leva o analista do discurso a compreender um texto além da esfera meramente lingüística, pois um texto é também prática discursiva e, como tal, abrange produção, distribuição e consumo. É na esfera da prática discursiva, mais notadamente na esfera da produção do texto, que se inscreve a intertextualidade, concretizada no intertexto. A esse propósito, o referido teórico afirma que "gêneros particulares são associados com 'modos particulares de intertextualidade' (manifesta)" (2001, p. 164). Essa concepção de Fairclough mostra-se verdadeira, ao menos no que diz respeito ao gênero carta ao editor.

A intertextualidade no corpus de nossa pesquisa revela-se bastante particular, fazendo-nos pensar que, em seu conjunto, as formas de remissão configuram-se como característica marcante do gênero em foco. Mas só podemos entender o fenômeno da intertextualidade em carta ao editor se considerarmos que o referido gênero possui um caráter eminentemente dialógico (cf. BAKHTIN, 2000), quer dizer, uma carta ao editor nasce como resposta direta a outro texto da mesma cadeia de gênero ${ }^{5}$ Todas as cartas publicadas pela revista estão necessariamente atreladas a um artigo, reportagem, entrevista, entre outros, publicados em edições anteriores. Assim, a carta ao editor estabelece um diálogo com o texto a que se refere, e esse diálogo é 
marcado por formas de intertextualidade particulares, o que chamamos de formas de remissão.

$\mathrm{Na}$ análise do corpus adotado, encontramos as seguintes formas de remissão ao texto-base: pressuposição, negação, ironia, alusão ao tema, referência ao título, excerto e paráfrase. No que diz respeito ao fenômeno da intertextualidade argumentamos, apoiando-nos em Fairclough (2001), que as formas de remissão supracitadas ajudam a delimitar o gênero cartas ao editor - na dimensão da prática discursiva - se vistas em composição com os outros aspectos. Fazemos a ressalva de que as referidas formas de remissão só ajudam nessa delimitação se foram tomadas em seu conjunto. Por exemplo, a paráfrase é uma forma de remissão encontrada em outros gêneros, assim como o excerto, pelo que não elucida nada quanto ao gênero cartas ao editor, se tomada isoladamente. Dito isto, podemos falar mais pormenorizadamente sobre a relação da intertextualidade com o gênero carta ao editor.

Apesar de Bakhtin (2000) afirmar que todo enunciado possui caráter dialógico, visto que nasce de outros enunciados, devemos argumentar que o gênero carta ao editor encontra no dialogismo um dos seus traços mais marcantes, pois qualquer carta enviada à redação da revista Newsweek a fim de ser publicada na seção Letters constitui-se em uma resposta direta a um texto anterior, publicado na mesma revista. Podemos perceber que o enunciado de um poema, por exemplo, ainda que tenha sua gênese em outro enunciado, não possui, necessariamente, essa relação direta com um texto determinado. $\mathrm{Na}$ carta ao editor, diferentemente, percebemos claramente o referido traço responsivo, pois, além de tudo, configura-se como resposta a outro texto da mesma cadeia de gênero, ou seja, um texto jornalístico. Além disso, as cartas enviadas à redação configuram a possibilidade de quebra da unilateralidade da referida cadeia, pois, como sabemos, elas, ao mesmo tempo que elogiam, criticam, corrigem, também têm a função de oferecer à publicação uma espécie de feedback do comportamento adotado perante seu público leitor, pois, como sabemos, órgãos da

\footnotetext{
${ }^{5}$ Fairclough (2003) chama de cadeia de gênero o conjunto de textos que são regularmente articulados, envolvendo transformações sistemáticas de gênero para gênero (por exemplo, documentos oficiais, reportagens na imprensa ou televisão).
} 
comunicação escrita e televisionada são formadores de opinião. Sendo assim, as mencionadas cartas funcionam como fator de equilíbrio. Por outro lado, dado o pequeno espaço destinado às cartas, podemos inferir que esse equilíbrio fica, de antemão, comprometido, uma vez que o restante do suporte é reservado à publicação.

Aqui, chamamos a atenção para a afirmação de Swales (1990), que diz ser a nomenclatura para gêneros de uma determinada comunidade de discurso uma fonte importante de percepção. Assim, o nome "carta ao editor" tem muito a revelar sobre o gênero que denomina. Em primeiro lugar, literalmente, trata-se de uma carta enviada ao editor de uma revista ou jornal, o que aponta para seu traço dialógico. Vale dizer ainda, a carta é enviada ao editor, e não especificamente ao indivíduo que ocupa o referido cargo. O editor de uma publicação tem, entre outras, a função de coordenar os trabalhos e de selecionar o que deve ser publicado, de acordo com a linha editorial da publicação. Nesse sentido, podemos dizer que, em última análise, é de sua responsabilidade a tarefa de evitar matérias que possam comprometer o nome da publicação, o que justifica que os leitores escrevam para ele não só para apontar algum equívoco cometido, criticando, mas também para dizer que a publicação está seguindo o caminho correto, elogiando, portanto.

Mas a interpelação feita pelo leitor-missivista, a priori, dirigida ao editor, acontece através de alguma forma de intertexto, ainda que tal intertexto não possa ser imediatamente identificado na carta. As modalidades de remissão ao texto-base por parte do leitor-missivista são por nós chamadas de formas de remissão. Queremos crer que tais formas de remissão, em seu conjunto, imprimem ao gênero carta ao editor um caráter particular. Mas é preciso observar que, conforme expressa Bakhtin (1986, p. 148), "o erro fundamental dos pesquisadores que já se debruçaram sobre as formas de transmissão do discurso de outrem, é tê-lo sistematicamente divorciado do contexto narrativo". Neste sentido, só é possível entender a intertextualidade como componente revelador das feições do gênero carta ao editor, se procurarmos entender como a recepção consciente dos enunciados se processa nas cartas.

Apoiando-nos nas concepções do citado lingüista russo, podemos dizer que a intertextualidade em carta ao editor deve se articular com todos os outros elementos compreendidos dentro da 
concepção tridimensional do discurso, trazida à tona por Fairclough (2001): texto, prática discursiva e prática social. Lembrando que nos detivemos apenas na prática discursiva, deixando de lado os estudos concernentes ao texto e à prática social.

Assim, no que se refere à esfera da prática discursiva, podemos entender a heterogeneidade mostrada (para Fairclough, intertextualidade manifesta) como o intertexto que, tendo sido incorporado dentro de um enunciado, provoca uma reorganização deste, de modo que esse enunciado se retextualiza a fim de acomodar o discurso alheio. No gênero carta ao editor, essa retextualização é fruto de uma acomodação em vários níveis; no entanto, por razões já expressas, focalizaremos apenas o nível da prática discursiva. Assim, queremos nos reportar à forma como o gênero em tela se articula dentro da cadeia de gênero em que se insere - o texto jornalístico. Dentro dessa perspectiva, a intertextualidade existente no gênero e sua conseqüente acomodação dentro do enunciado obedecem a fatores como: o suporte, o canal, o enunciador (sua posição social e seus propósitos comunicativos), o co-enunciador (sua posição social), a cadeia de gênero em que se insere o gênero, de forma que o estudo das implicações da intertextualidade dentro de dado gênero se torna bastante complexa.

Em linhas gerais, podemos dizer que, no que se refere ao fenômeno da intertextualidade e do dialogismo, a carta ao editor apresenta características que não são compartilhadas em sua totalidade com outros gêneros, inclusive com os que pertencem à mesma cadeia de gênero. Como exemplo, podemos citar a relação direta entre o texto-base (artigo, entrevista, reportagem) e a carta ao editor (elaborada como resposta ao texto-base). Pois, no primeiro caso, a manifestação da intertextualidade se dá diferentemente do segundo, muito embora pertençam à mesma cadeia de gênero.

3 Formas de remissão nas cartas ao editor de Newsweek: a pressuposição e a ironia

\subsection{A pressuposição}

Para Ducrot (1987), as pressuposições correspondem a realidades supostas já conhecidas do destinatário; não podem ser afetadas pela negação ou interrogação; e, em princípio, não podem ser 
anuladas. No corpus da presente seção, a pressuposição é a forma de remissão mais utilizada pelos leitores-missivistas, seguida da parafrasagem.

Elegemos a carta de número 36, transcrita abaixo, para efeito de exemplificação e análise desse fenômeno de heterogeneidade mostrada. Conforme esclarecido em nossa fundamentação teórica, ao fenômeno da pressuposição está subjacente a idéia de que, dentro do enunciado em que existe pressuposição, há sempre o que é pressuposto e o que é posto. Conseqüentemente, há sempre a presença de dois enunciadores.

(36) to attack when necessary is bad enough, but to go to war on an if, a might and a maybe leaves me speechless. And now, eloquent speech writers will make something noble out of this macho militancy.

Michael G. Driver ICHIHARA, JAPAN

O leitor-missivista dessa carta a inicia com uma avaliação sobre a possibilidade de uma guerra entre Estados Unidos e Iraque. Segundo sua avaliação, atacar quando necessário já é suficientemente ruim, porém algo pior acontece quando as razões para fazer a guerra estão marcadas pelo "se", pelo "talvez" e pelo "pode ser" (if, might, maybe), o que em outras palavras significa dizer: sem razões confiáveis. Aqui a forma de remissão é feita pelo posto, que remete ao pressuposto, pois o autor não fornece informações detalhadas sobre o artigo que deu origem a essa missiva. $\mathrm{O}$ autor faz referência clara a uma enunciação que não autoriza pela menção na carta do "se", do "talvez" e do "pode ser", cujo caráter intertextual, nesse caso, é dado pela substantivação (an if, a might, a maybe), levando o leitor da missiva a procurar reconstruir o texto, pressupondo que os argumentos (pressupostamente em favor da guerra) do texto-base se constroem em torno de possibilidades, dúvidas e condições.

Pela forma genérica com que o autor da carta, através dessa forma de heterogeneidade mostrada, refere-se ao texto base, podemos classificar a aludida forma de remissão como uma abordagem generalizante da temática. Isto pode ser constatado na progressão do texto em análise. O leitor-missivista conclui seu texto dizendo que os 
redatores de discurso tratarão de tornar o comportamento reprovável (de fazer guerra) em algo que venha a ser aceito como "nobre" (heróico).

Pela leitura dessa missiva, podemos perceber que ela compreende o posto, enquanto que os pressupostos podem ser recuperáveis através dos elementos textuais fornecidos pelo autor. $\mathrm{O}$ primeiro pressuposto, marcado pela oração "atacar quando necessário já é suficientemente ruim" (to attack when necessary is bad enough), é: existem preparativos para uma guerra, pois contextualmente o leitor "deve ter conhecimento" que até a data da publicação da carta, a guerra a que o leitor-missivista se referia não havia sido deflagrada. O segundo é: os argumentos que justificam o fazer a guerra são construídos em torno de possibilidades, de suposições, e de condições, evidenciados textualmente pelo uso do "se", do "talvez", e do "pode ser".

A última sentença dessa carta remete o leitor a pensar sobre algo que não foi veiculado em nenhum dos dois enunciados em que foi estabelecido o fio dialógico. O leitor-missivista chama a atenção para a possibilidade de que, no futuro, manipuladores do discurso venham a encontrar meios de fazer com que a situação real (da guerra injustificada) seja revertida para algo aceitável por parte da população, notadamente a população americana.

Sendo a pressuposição a forma de remissão mais utilizada em nosso corpus, devemos tentar entender, buscando suporte em Bakhtin (1986), qual o significado de seu uso nas cartas enviadas ao editor da Newsweek. A princípio podemos dizer que essa forma de remissão tem o respaldo social necessário que faz com que os leitores queiram utilizá-la. Mas o elemento social por si só não diz tudo. Devemos entender que o seu uso harmoniza-se com as feições de um gênero que possui características muito próprias, ainda que tentemos entendêlo com base em aspectos meramente contextuais. Ao usar a referida forma de remissão, o leitor-missivista pressupõe que seu leitor tenha lido o artigo a que se refere. Por outro lado, a mencionada forma de remissão aponta para um apagamento, ainda muito maior que a paráfrase, dos limites do intertexto dentro do enunciado que o incorpora. Podemos ver o intertexto apenas através da análise feita sobre ele pelo autor da missiva, o que aponta para o quão a temática por ele abordada deve ser familiar aos interlocutores. 


\subsection{A ironia}

A forma de intertextualidade chamada ironia se caracteriza pela presença de um enunciado que não é assumido pelo enunciador, em parte ou em sua totalidade, no momento da enunciação. Neste caso, o enunciador procura criar um efeito de surpreender seu interlocutor, pois o enunciado se apresenta como um ponto de vista insustentável e atribuível a uma outra personagem. Trata-se de uma forma de heterogeneidade mostrada bastante complexa que vem sendo alvo de reflexão desde a origem da Filosofia (cf. CHARAUDEAU; MAINGUENEAU, 2004). A primeira carta em que reconhecemos a presença da ironia como forma de remissão é a carta de número 39 (de nosso corpus), transcrita a seguir:

(39) THE UNited STATES IS TOTALLY JUSTIFIED in targeting a rogue Middle Eastern country that has weapons of mass destruction, invades its neighbors, defies U.N. resolutions and international laws, and oppresses and terrorizes minorities and opponents to its regime. The country I'm thinking of is Israel: it has nuclear weapons, has invaded Egypt, Syria, Jordan and Lebanon, has consistently defied all U.N. resolutions pertaining to it and inflicts the worst kinds of terror on its Arab population. We should go and effect a regime change in Israel whether it accepts weapons inspectors or not.

Ali MiLI

NEWARK, NEW JERSEY

Nessa carta o leitor-missivista diz que "os Estados Unidos estão corretos em invadir um país vagabundo do Oriente Médio que tem armas de destruição em massa, invade os seus vizinhos, desafia as leis das Nações Unidas, oprime e aterroriza as minorias e oponentes do seu regime", para depois dizer que o país a que está se referindo é Israel. A ironia aqui está no fato de utilizar todos os atributos que os Estados Unidos utilizam para definir o Iraque. Depois, o autor da carta quebra a expectativa do leitor dizendo que se refere a Israel.

A decisão de utilizar a ironia como forma de remissão alcança aqui um efeito um tanto incomum, demonstrando ser um meio 
eficiente de argumentação. Considerando que o espaço destinado ao leitor-missivista é bastante pequeno, comparado com o espaço de que dispõe o articulista, a referida forma de remissão cumpre mais de um papel: 1) utilizar um mínimo de espaço com o máximo de eficiência, ao demonstrar que Israel se enquadra perfeitamente dentro dos atributos e argumentos utilizados pelos Estados Unidos para invadir o Iraque; 2) mostrar a contradição e a parcialidade dos argumentos americanos para justificar a invasão ao Iraque.

Chamamos a atenção para o modo como a estratégia remissiva utilizada se mostra eficiente no sentido de criar no leitor certa expectativa, para depois quebrá-la de uma forma surpreendente. Se, no início, o leitor não percebe a contradição, a tomada de consciência do contra-senso ocorre de forma quase que imediata, pois as primeiras frases da carta o levam a pensar que o seu autor se posiciona a favor dos critérios de julgamento americanos, para depois mostrar, implicitamente, que esses critérios não estão sendo aplicados a Israel. É importante destacar que, na missiva, o leitor não diz que o Iraque não se enquadra nos referidos atributos, querendo, talvez, mostrar que os Estados Unidos não aplicam os mesmos critérios de avaliação a todos, o que leva a concluir que as razões verdadeiras para a invasão do Iraque são outras.

O principal argumento utilizado para justificar a invasão dos Estados Unidos ao Iraque - ter armas de destruição em massa provou ser falso, hoje sabemos. Paralelamente, Israel é o país mais fortemente armado do Oriente Médio, o que prova a força da argumentação do leitor-missivista da carta 39.

É interessante observar que não nos sentimos autorizados a usar a ironia em situações formais de interação social em que se estabelece uma relação de confiança e respeito mútuo entre, pelo menos, dois interlocutores. No entanto, o uso da ironia está associado a situações em que possivelmente essa relação de confiança e de respeito foi quebrada. A lei da sinceridade não está sendo cumprida e para demonstrar isso, o interlocutor, irônico, passa a usar da mesma insinceridade, ao mesmo tempo em que deixa claro que não está sendo sincero, pelo "absurdo" do que diz, muitas vezes utilizando-se de recursos supra-segmentais reconhecidamente reveladores do comportamento irônico. $\mathrm{Na}$ carta em análise, como sabemos, o seu autor não pode lançar mão desses recursos. Consegue ser irônico ao 
incorporar o discurso do seu interlocutor para depois aplicá-lo ao objeto "errado". Talvez por apontar de uma forma tão contundente para o interlocutor como descumpridor da lei da sinceridade é que a ironia seja um recurso pouco utilizado em gêneros cujas características estejam ligadas à noção de democracia e liberdade de expressão, como é o caso de carta ao editor, pois ao ser irônico, o enunciador mostra que na verdade o seu interlocutor não quer ouvi-lo, indicando, conseqüentemente, o quão anti-democrático é o discurso do outro, especialmente quando o outro se arvora de democrático. Adotando um comportamento irônico, o locutor da carta aponta para o fato de que o seu co-enunciador não merece crédito.

A carta de número 71 também apresenta a ironia como forma de remissão, embora a referida forma de heterogeneidade mostrada se realize de maneira diferente da carta 39. Na carta 71, a remissão irônica aparece somente no final, pois todo o restante do conteúdo da missiva se refere às características negativas do governo de Saddan Hussein. Ao longo de quase toda a exposição dessas características negativas, o missivista dá a entender que se alinha com a abordagem política de Bush, para no final mostrar que o presidente americano não tem razão para condenar o governo iraquiano, uma vez que ambos compartilham características similares. O que há de irônico na carta é a forma como o leitor missivista mostra essas similaridades com o uso da palavra so nas duas últimas sentenças: Leiamos a carta:

(71) since saddam seized power without any democratic mandate, his nation has suffered economic decline and become contemptible in the eyes of the world due to his bellicosity and unilateralist disdain for environment and the United Nations. At the same time, his weapons of mass destruction strike fear in our hearts. And he and his cronies have grown rich by corrupt dealings in oil and other industries. Why does Bush hate him so? They have so much in common.

DAVID IRBY

DINGLE, IRELAND

Nesse caso, o locutor assume o conteúdo da enunciação, mas há uma discordância da atitude esperada para essa situação, o que 
provoca um efeito de choque sobre o leitor comum, especialmente sobre aqueles que se mostram a favor das atitudes do chefe do Estado americano.

\section{Considerações finais}

Se pensarmos em termos de propósitos a serem atingidos, podemos fazer conjecturas que se aproximem da realidade do gênero em questão. O caso da ironia se configura como proveitoso exemplo para esse tipo de análise. Nos dois casos analisados, podemos perceber o quão o efeito criado exerce um papel importante, pois gera uma espécie de epifania no leitor comum, que passa a perceber, se ainda não percebia, implicações de atitudes e posicionamentos teóricos que de outra forma demandaria uma longa argumentação.

Já a pressuposição remete para a questão da familiaridade e do conhecimento que o leitor comum tem com o assunto abordado no texto-base. Neste sentido, a revista presta auxílio a esse leitor, colocando ao lado das cartas a gravura relacionada ao texto referido pelas cartas publicadas naquela edição. A pressuposição vem ao encontro às intuições das Bronckart (2003), que afirma que a realização de um gênero depende de elementos circunstanciais.

As formas de heterogeneidade mostrada, abordadas aqui, denunciam o caráter fortemente dialógico do gênero do discurso carta ao editor, ao mesmo tempo em que se articulam com os propósitos comunicativos e com os efeitos almejados pelos leitores-missivistas, que, por sua vez, devem possuir a competência genérica necessária a fim de que suas escolhas enunciativas surtam o desejado efeito. A esse propósito, a pressuposição, como a forma de remissão mais utilizada nas cartas, sugere uma tensão entre o uso da argumentação objetiva, e o uso de uma forma de argumentação menos calcada na abordagem objetiva e referencial dos temas. Em todo caso, seguindo de perto Bakhtin (1986), não podemos esquecer que as formas de intertextualidade aqui analisadas devem ser respaldadas pelo meio social em que são utilizadas. Uma prova disso é que o uso da pressuposição se destaca visivelmente na preferência dos leitores-missivistas, pelo menos no corpus que estudamos.

Ao longo da análise, observamos que as formas de remissão não são escolhidas aleatoriamente, mas guardam estreita relação com 
a maneira como o autor dá progressão a seu texto. Assim, podemos dizer, grosso modo, que existem formas de remissão que permitem uma exploração mais ampla da temática abordada pelos textos dialogantes. De outro lado, existem formas de remissão que só permitem um tratamento mais restrito das temáticas exploradas nesses textos, queremos dizer, onde há marcas textuais mais visíveis no processo argumentativo dentro do texto.

\section{Referências}

BAKHTIN, M. Estética da criação verbal. 3. ed. São Paulo: Martins Fontes, 2000.

Marxismo e filosofia da linguagem. São Paulo: Hucitec, 1986.

BRONCKART, J. P. Atividade de linguagem, textos e discursos: por um interacionismo sócio-discursivo.São Paulo: EDUC, 2003.

CARDOSO, Maurício Moreira. O gênero Carta ao Editor em Newsweek: aspectos discursivos e sócio-interacionais. 2005. 149f. Dissertação (Mestrado em Lingüística Aplicada) - Universidade Estadual do Ceará, Fortaleza.

CHARAUDEAU, P.; MAIGUENEAU, D. Dicionário de análise do discurso. São Paulo: Contexto, 2004.

DUCROT, O. O dizer e o dito, Campinas: Pontes, 1987.

FAIRCLUGH, N. Discurso e mudança social. Brasília: Editora da UnB, 2001.

MAINGUENEAU, D. Novas tendências em análise do discurso. Campinas: Pontes, 1997.

Análise dos textos de comunicaşão. São Paulo: Cortez, 2001. 
ORLANDI, E. Análise do discurso: princípios e procedimentos. Campinas: Pontes, 2003.

SWALES, J. M. English in academic and research settings. Cambridge: Cambridge University Press, 1990. 